\title{
Advances in the Genetics of Anti-Glomerular Basement Membrane Disease
}

\author{
Xu-Jie Zhou Ji-Cheng Lv Ming-Hui Zhao Hong Zhang \\ Renal Division, Department of Medicine, Peking University First Hospital, Institute of Nephrology, \\ Peking University and Key Laboratory of Renal Disease, Ministry of Health of China, Beijing, PR China
}

\section{Key Words}

Anti-glomerular basement membrane disease •

HLA-DRB1*1501 $\cdot$ FCGR $\cdot$ KLK

\begin{abstract}
Anti-glomerular basement membrane (GBM) disease is a rare but lethal autoimmune disorder. Over the past few years, the nature of the autoantigen and its epitopes has been defined, as well as the possible pathogenic role played by environmental factors, and by cellular and humoral immunity. However, the majority of data on anti-GBM disease comes from studies conducted on animal models, since human studies are relatively scarce. Genetic studies have highlighted strong positive associations of anti-GBM disease with the HLA-DRB1*1501 allele. In addition, the disease has been associated with genes of the FCGR and KLK families. Important as they are, these findings have to be considered preliminary, if not contentious. Here, we provide an overview of recent discoveries in the genetics of anti-GBM disease that may help elucidate the disease pathogenesis while improving therapeutic approaches. We also discuss the limitations of such discoveries. Finally, we suggest that extensive collaboration between investigators and novel integrative approaches are essential to the progress of our understanding of the anti-GBM disease. We attempted to summarize the
\end{abstract}

current knowledge on the pathogenesis of anti-GBM disease by providing different but complementary perspectives from previous reviews.

Copyright $\odot 2010$ S. Karger AG, Basel

\section{Introduction}

Anti-glomerular basement membrane (GBM) disease (also known as Goodpasture's disease/syndrome) is a rare autoimmune disorder characterized by circulating autoantibodies directed to specific antigenic targets within the glomerular and/or pulmonary basement membrane. The anti-GBM disease incidence (0.5-1 case/million/ year) is vastly lower compared to that of other autoimmune kidney diseases, such as antineutrophil cytoplasmic antibodies (ANCA)-associated vasculitis (10-20 cases/million/year) or lupus nephritis (20-100 cases/million/year) [1]. Although rare, anti-GBM disease is often lethal, as most of the patients present with rapidly progressive glomerulonephritis that accounts for up to $20 \%$ of acute renal failure $[2,3]$. Untreated anti-GBM disease has an almost universally poor outcome with death from renal failure or lung hemorrhage. Even with extensive treatment, kidney damage is irreversible. Thus, patients with severe renal involvement are often left with perma- 
nent renal failure and face a life of renal replacement therapy. Due to its acute onset, rapid progression, irreversibility and high mortality, anti-GBM disease represents a great challenge in the field of nephrology.

Over the past few years, there has been considerable progress in our understanding of anti-GBM disease. The nature of the autoantigen and its epitopes has been defined as well as the possible pathogenic role played by environmental factors and by cellular and humoral immunity [2, 4-10]. A large body of evidence indicates that genetics might play an important role in anti-GBM disease. Hence, mapping genes associated with anti-GBM disease could help identify biomarkers or therapeutic targets that could be used to optimize the diagnosis and prognosis of the disease and to develop personalized medicine approaches. Importantly, mapping genes associated with anti-GBM disease could help generate new hypotheses about the disease mechanisms and pathogenesis. In this review, we summarize recent discoveries in the genetics of anti-GBM disease, focusing on results obtained in animal models and in human genetic association studies. We also discuss the significance and limitations of such discoveries. Finally, we suggest that extensive collaboration between investigators and novel integrative approaches are essential for the progress of our understanding of anti-GBM disease. We review the current knowledge on the pathogenesis of anti-GBM disease in a genetic manner, providing partly different but complementary perspectives compared with previous reviews. We hope such perspectives can provide a renewed understanding of anti-GBM disease and further optimize therapy in the future.

\section{Genetics of Anti-GBM Disease}

Similarly to many other autoimmune diseases, antiGBM disease is hypothesized to be triggered in genetically predisposed individuals by some sort of environmental stimuli. There are several pieces of evidence that suggest a genetic component of anti-GBM disease. For instance, it is known that the disease can occur in siblings and sets of identical twins [2]. In addition, studies based on sporadic cohorts indicated a strong positive as well as negative association with specific human leukocyte antigen (HLA) molecules. For instance, HLA-DR15 and HLA-DR4 are positively associated with anti-GBM disease, while HLA-DR7 and HLA-DR1 are negatively associated $[11,12]$. The heterogeneity of the symptoms might also reflect a complex genetic background. In fact, although the diagnosis of the disease is always determined by the presence of circulating anti-GBM autoantibodies, histological features of severe crescentic glomerulonephritis and linear IgG deposits on the GBM, the nature and severity of the symptoms and involved organs vary significantly among patients. Symptoms range from normal renal function to rapidly progressive glomerulonephritis, and in some cases the disease can extend to other organs developing into a systemic disorder $[4,13]$.

As in other complex autoimmune disorders, immune dysregulation that makes a genetically predisposed individual develop anti-GBM disease can occur at multiple levels. Immune dysregulation could result from a breach in central and peripheral tolerance, amplification of the autoimmune response, and local processes in the target organ that facilitate end-organ disease. Individual genotypes can affect one or more components of the adaptive or innate immune systems, eliciting an altered immune response to self antigens. The precise mechanisms of the breakdown of immune tolerance are unclear and the existing hypothesis may oversimplify the molecular events that lead to anti-GBM disease. In contrast, the mechanisms by which immune responses to autoantigens cause organ damage are relatively well described. Thus, in this review, we will discuss the advances in the genetics of anti-GBM disease focusing on the following aspects: presence of autoantigen and antigen presentation, humoral immunity (autoantibody, Fc receptors and complement), cellular immunity (mainly T cell), and downstream molecular pathways that facilitate end-organ damage.

\section{Autoantigen and Antigen Presentation}

As the anti-GBM autoantibody has been a main focus in the past few years, the target autoantigen in anti-GBM disease has been identified as the $\alpha 3$ chain non-collagen 1 domain of type IV collagen [ $\alpha 3(\mathrm{IV}) \mathrm{NC1}$ ]. Two conformational epitopes of anti-GBM autoantibodies have been defined as $\mathrm{E}_{\mathrm{A}}$ and $\mathrm{E}_{\mathrm{B}}$ [14]. In a study performed on 15 patients, no mutations were found by direct sequencing exons 48-52 of the COL4A3 gene, which encodes $\alpha 3(I V) N C 1$ [15]. Similarly, in a rat model of anti-GBM disease, no linkage between disease susceptibility and rat COL4A3 gene was found [16]. These data suggest that alterations of the amino acid sequence translated by the COL4A3 gene are not a major factor in the disease etiology, but may represent pathogenic conformational change [10]. Vanacore et al. $[17,18]$ suggested that $\mathrm{E}_{\mathrm{A}}$ and $\mathrm{E}_{\mathrm{B}}$, as 
cryptic B cell epitopes, were enclosed in the quaternary structure of the hexamers created by sulfilimine crosslinks between the trimers of adjacent $\mathrm{NC1}$ chains; dissociation of the $\mathrm{NC1}$ hexamers and exposure of the pathogenic epitopes on the $\alpha 3$ and $\alpha 5$ chains may be the inciting event that leads to the production of the anti-GBM autoantibody [10]. This concept further advances our understanding of the conformational nature of the epitopes of anti-GBM disease [19]. But how these conformationdependent epitopes are initiated is still obscure. As suspected, the triggering event may be an individual factor or a combination of factors, i.e. genetic susceptibility, posttranslational modifications, epitope spreading and environmental factors. If there is a contribution of genetic susceptibility, genetic polymorphisms influencing conformation of an epitope, rendering it susceptible to autoantibody binding, may need to be addressed.

As the T cell epitope was reviewed by Ooi et al. [6] and the only human $\mathrm{T}$ cell epitope mapping study to date gives a somewhat different result, we will not extensively discuss this here.

Major histocompatibility complex (MHC) molecules are required for the presentation of (auto-)antigens to $\mathrm{T}$ cell receptors. The process of antigen presentation is exquisitely regulated by the level of MHC molecule expression and by the specific MHC alleles expressed. This is likely to be a major mechanism by which HLA molecules regulate the peripheral $\mathrm{T}$ cell repertoire and overall $\mathrm{T}$ cell immune responsiveness in a given individual. Genetic defects in self-tolerance can be caused by reduced or altered expression of MHC molecules [20]. Similarly to many other autoimmune diseases, genes within the MHC on the short arm of chromosome 6p21.3 exhibit a strong association with the risk of anti-GBM disease [11, 12]. The genetic association with anti-GBM disease among different populations has previously been linked to MHC class II genes, especially with the HLA$\mathrm{DRB1}^{*} 1501$ allele [11]. Although HLA-DRB1*1501 is strongly associated with anti-GBM disease, we must be cautious in defining it as a molecular biomarker for the following reasons:

- Nonrandom association or linkage disequilibrium (LD) exists in the inheritance of alleles at multiple loci within the MHC [21]. The extended haplotype homozygosity analysis for recent positive selection shows that all 14 outlying haplotype variants map to a single extended haplotype that most commonly bears HLADRB1*1501. Such tight segment-to-segment LD can pose an important obstacle in MHC research: if a disease association with HLA-DRB1*1501 was found, it may not be possible to determine whether the variant HLA-DRB1*1501 is causal or whether its association simply reflects LD with the truly causal variation.

- Some of the genes within the MHC (such as the classical class I genes, HLA-A, $-\mathrm{B}$, and -C and the classical class II genes, HLA-DRB1, -DQA1, and -DQB1) exhibit extensive variability, and consequently require typing strategies that are both labor- and time-intensive. Indeed, HLA-DRB is the most polymorphic gene in the human genome, though as of yet insufficiently investigated.

- The mechanism underlying MHC association with autoimmune diseases is not clearly understood. One long-held view suggests that the breakdown of immunological tolerance to autoantigens can be due to aberrant class II presentation of self or foreign peptides to autoreactive T lymphocytes. Thus, it seems likely that specific MHC class II alleles could be involved in the presentation of particular autoantigens resulting in disease-specific associations. However, the HLADRB1 genetic polymorphisms, collectively termed the 'shared epitope' (HLA-SE), and HLA-DRB1*1501 have been associated with numerous autoimmune diseases. Thus, the association with HLA-DRB1*1501 is not specific for anti-GBM disease [20, 22]. In addition, $\mathrm{DR}^{*} 15$ exhibits a lower affinity to $\alpha 3$ (IV)NC1 peptide when compared to DR1 and DR7, which are negatively associated with anti-GBM disease [23].

- Most studies of MHC association published to date are relatively small in sample size, each testing a limited number of variants using a variety of typing methodologies. Interpretation of the results is therefore very difficult. Thus, it is not surprising that another association with HLA genetic variations, except HLADRB1*1501, can hardly be replicated. The underpower to detect the moderate effect of common variants is the biggest problem in the current genetic studies of anti-GBM disease.

- Although a strong association exists between antiGBM disease and HLA-DRB1*1501, this allele is also common in healthy populations.

In light of all these considerations, we suggest HLA as an important susceptibility genetic locus to anti-GBM disease, but we should be prudent before introducing HLA-DRB1*1501 into the clinical practice as a diagnostic tool. Future studies should complete a fine mapping of the $\mathrm{MHC}$ region in anti-GBM disease and investigate the precise molecular basis of MHC association with the disease. 


\section{Autoantibody, Fc Receptor for IgG (Fc $\gamma R)$ and Complement}

A large body of evidence supports the role of autoantibodies in the pathogenesis of anti-GBM disease (regardless of their titer, avidity, or isotype) [24-27]. It was suggested that the pathogenic antibodies were not encoded by a unique subset of genes and that normal individuals have the capacity to produce them [28]. The presence of autoantibody and/or subsequent tissue deposition of immune complexes (IC) are thought to cause organ lesions. Likely, the receptors involved in autoantibody/IC-mediated damage are Fc $\gamma$ Rs. Data from Fc $\gamma \mathrm{R}$ gene knockout mice indicate an uncoupling linkage between IC formation and kidney damage [29]. Fc $\gamma \mathrm{R}$ common $\gamma$ chain gene knockout mice present no significant change of serum total immunoglobulin, IgG isotype and specificity, and IC deposition in kidney, but the severity of kidney disease is significantly reduced compared to wild-type mice. Such an uncoupling phenomenon suggests an important role of $F c \gamma R$ in the effector response of autoantibodies in anti-GBM disease. In immune response signaling, Fc $\gamma$ RIIB is the sole inhibitory receptor in the Fc $\gamma \mathrm{R}$ family [30-32]. Studies performed on genetargeted mice lacking specific Fc $\gamma \mathrm{R}$ (activating or inhibitory Fc $\gamma \mathrm{R}$ ) have demonstrated different susceptibility to anti-GBM disease. Fc $\gamma$ RIIB-deficient mice can develop anti-GBM disease upon immunization with type IV collagen, whereas activating Fc $\gamma$ Rs-deficient mice are protected from IgG-mediated glomerulonephritis $[33,34]$. Studies of transgenic mice further reinforced the idea that Fc $\gamma$ Rs play independent roles in the pathogenesis of the disease [35]. Although results obtained in mouse models can provide important insights into human immune function and disease, they require careful validation. This is because there are many known immunological differences between these two species, and because the Fc $\gamma \mathrm{R}$ gene family is more complex in humans than in mice. For instance, Fc $\gamma$ RIIA and Fc $\gamma$ RIIIB are present only in humans; consequently, data based on mouse myeloid cells may not have taken into consideration signaling pathways mediated by these two receptors. In addition, the complexity of the FCGR gene family does not only lie in its high sequence homology between FCGR genes but also in different genetic variations, including single nucleotide polymorphism (SNP) and copy number variation (CNV). Of note, CNVs were observed for FCGR2C, FCGR3A and FCGR3B in humans but not in the mouse $\mathrm{Fc} \gamma \mathrm{R}$ gene locus. Allelic variants of FCGR2A-131H/R (rs1801274), FCGR2B-232I/T (rs1050501), FCGR3A176F/V (rs396991) and FCGR3B $\mathrm{NA} 1 / 2$ have been reported to be associated with various autoimmune diseases [30-32]. We previously provided a set of preliminary data supporting a role of genetic variations of the FCGR gene family in the risk of anti-GBM disease $[36,37]$. Specifically, in a Chinese cohort, we found an association of FCGR2B-232T (rs1050501) and FCGR3A CNV with susceptibility to anti-GBM disease. In the FCGR2B, a nonsynonymous $\mathrm{T}$ to $\mathrm{C}$ transition in exon 5, 232I/T (rs1050501) results in the substitution of a threonine for isoleucine at position 232 within the transmembrane domain of Fc $\gamma$ RIIB. FCGR2B-232T is unable to inhibit activating receptors because it is excluded from sphingolipid rafts, resulting in an unopposed proinflammatory signaling [38]. Based on these observations, we speculated that FCGR2B-232T may be a variant able to promote anti-GBM disease. Copy variation of FCGR3A might represent another susceptibility factor in anti-GBM disease. Deletion of the mouse activating receptor FCGRIV (analogous to the human FCGR3A) protected mice from developing accelerated anti-GBM disease [34], while in humans more copies of FCGR3A may alter phenotypes by dosage effect (more copies along with higher gene expression can lead to greater activating effects) [39]. Although these results are interesting, one should keep in mind the following considerations while interpreting them:

- The FCGR gene family exhibits great genetic heterogeneity. The frequency of gene variants in different populations fluctuates substantially; for example, FCGR2B-232T/T exhibits 1\% homozygosity in Caucasians but $5-11 \%$ homozygosity in Africans and Southeast Asians [32]. The association between FCGR2A-131R and lupus was more affirmative in Caucasians, whereas the association between FCGR2B-232T and lupus was more prominent in Asian populations. In addition, the association between the low copy number of FCGR3B and lupus has been confirmed in the Caucasian population but not in three different cohorts of the Chinese population [40-42]. Whether the above inconsistencies reflect a population-specific effect, insufficient power due to limited sample size, or poor genotyping methodology [43] (due to high sequence homology among FCGR genes and/or $\mathrm{CNV}$ as discussed below) remains to be determined.

- Although FcyRs might play a role in the pathogenesis of a systemic autoimmune disease, their precise role in human anti-GBM disease remains unclear. Functional studies are still lacking due to the rarity and sever- 
ity of the disease. The correlation between genotype and definite phenotype should also be addressed.

- The involvement of SNP and CNV in the disease pathogenesis is not totally overlapping. It was reported that SNPs and CNVs captured 83.6 and $17.7 \%$ of the total detected genetic variation in gene expression, respectively, but the signals from the two types of variation had little overlap [44]. The presence of CNV might lead to skewing of the genotype frequencies by causing genotyping errors. For example, one copy of FCGR3B may lead to mistyping of FCGR3B NA1/null as homozygous NA1/NA1 or three copies of FCGR3B may lead to mistyping of FCGR3B NA1/NA1/NA2 as homozygous NA1/NA1 or heterozygous NA1/NA2. In addition, so far there is no best method to detect complex CNVs [43]. Thus, it is important to integrate different genetic variations in genetic association studies on anti-GBM disease. Further additional studies are warranted, including studies on larger sample size with the same genetic background as well as validation studies in populations with a different genetic background. Also functional assays, conducted on a sufficient number of subjects with different genotypes, are needed; targeting specific FCGR gene variation or mutation will allow elucidation of concrete mechanisms.

Besides Fc $\gamma$ Rs, ICs can also activate complement components. Activation of the complement system involves participation of a large number of plasma proteins including C1q, C1r, C1s, C2 through C9, factor B, factor D, and properdin. Upon IC deposition, three complement pathways (classical, alternative and lectin pathways) can be activated. The role of the complement in systemic autoimmune diseases, including anti-GBM disease, has recently been reviewed by Chen et al. [45]. Studies conducted on Fc $\gamma \mathrm{R}$ knockout mice reached conflicting conclusions on the role played by the complement: some studies indicated no participation $[29,46]$, while others indicated a protective $[47,48]$ or a detrimental role $[49,50]$. A recent study conducted in mice suggested that it is the classical pathway, rather than the lectin pathway, which plays a significant role in anti-GBM disease [50]. Interestingly, the alternative pathway is important in mice deficient in the classical pathway $\left(\mathrm{Clq}^{-/-}\right.$mice) or in the classical and the lectin pathways ( $\mathrm{C}^{-/-}$mice) [50]. These inconsistent results may be due to different mouse models showing different severity of renal damage. Any factors involved in the ongoing process of disease progression, such as degree, time span, isotype, and the species origin of the IgG, can influence the disease severity. For instance, comple- ment activation is obligatory when the levels of auto-IgG are high $[49,50]$. Further analysis of the contribution of the complement in the process of anti-GBM antibodymediated renal damage in mice, as well as in humans, is needed.

\section{T Cell-Mediated Immunity}

Although autoantibodies have been the major focus of studies investigating effector mechanisms in anti-GBM disease, several lines of evidence have implicated that also cell-mediated immunity (especially CD4 $+\mathrm{T}$ cells and $\mathrm{CD} 8+\mathrm{T}$ cells) plays a role in anti-GBM disease $[51,52]$. In rats, anti-GBM disease can be induced simply by transferring $\alpha 3(\mathrm{IV}) \mathrm{NC} 1$-specific CD4+ T cells, suggesting a pathological role of such cells [51]. On the other hand, the observations that anti-CD8 monoclonal antibodies reduce disease severity, and the fact that antigen-specific $\mathrm{CD} 8+$ clones have been isolated from patients with antiGBM disease, support the importance of CD8+ T cells in the pathogenesis of the disease [52]. More recent studies emphasized the role of invariant natural killer $\mathrm{T}$ (iNKT) cells and of the Th17 subset in anti-GBM disease $[53,54]$. iNKT cells function as innate effector cells: by rapidly releasing large amounts of effector cytokines and chemokines, they play an important role in modulating immune responses. It has been observed that after injection of anti-GBM serum, the number of kidney iNKT cells rapidly increases. In addition, iNKT cell-deficient mice $\left(\mathrm{J}_{\mathrm{a}} 18^{-/-}\right)$injected with anti-GBM serum demonstrate worse renal function, more proteinuria, greater injury of glomeruli as well as tubules, and lower expressions of TGF- $\beta$ and TGF- $\beta$-induced genes compared with similarly treated wild-type mice [54]. Th17 cells are a subset of CD4+ T cells that produce the proinflammatory cytokine IL-17. Mice deficient in IL-23, which is important for the maintenance of Th17 cells, are protected from antiGBM disease, exhibiting lower autoantibody titers, reduced cellular reactivity, diminished cytokine production [IFN- $\gamma$ (Th1), IL-17A (Th17), TNF, and monocyte chemoattractant protein 1], and decreased glomerular IgG deposition [53]. Notwithstanding these results, the genetic linkage between anti-GBM disease and T cellmediated immunity remains obscure. Genetic studies targeting variants in genes codifying for costimulator molecules, signaling molecules and related cytokines may provide further clues for elucidating the mechanism of $\mathrm{T}$ cell-mediated immunity in the pathogenesis of antiGBM disease. 


\section{End-Stage Organ Failure and Kallikrein System}

It has long been known that anti-GBM disease induced in mice (experimental anti-GBM antibody-induced glomerulonephritis) is somewhat strain specific [55]. The strain differences cannot be solely attributed to differences in systemic immune responses. Renal intrinsic processes may also contribute to the observed strain differences. A microarray-based transcriptomic analysis of the renal cortex obtained from 3 experimental antibody-induced glomerulonephritis-sensitive strains and 2 control strains revealed a significant fraction of underexpressed genes that distinguishes the nephritis-sensitive strains from the control strains. Such genes belong to the kallikrein (KLK) gene family [56]. Kallikreins constitute a multigene family of serine esterases with a wide spectrum of biological functions, including regulation of inflammation, apoptosis, redox balance, kidney fibrosis, and local blood pressure. Emerging evidence suggests that many kallikreins are implicated in the pathogenesis of different diseases, such as essential hypertension, intracranial aneurysms, end-stage renal disease, and cancer [57]. Liu et al. [56] had provided data that suggest a protective role for kallikrein in animal models of anti-GBM disease and lupus nephritis, and an association of human lupus nephritis with kallikrein 1, 3 (KLK1, 3). Such pieces of evidence for a protective role for kallikrein in end-stage organ failure and autoimmune diseases support the concept of shared genetics between anti-GBM disease and lupus nephritis, and go against the belief that anti-GBM disease is radically different from other autoimmune diseases, i.e., anti-GBM disease is a somewhat organ-specific autoimmune disease that rarely relapses or coexists with other autoimmune diseases. Although these findings are very important, they should be replicated before they can be deemed valid $[56,58]$. Furthermore, the association of the KLK gene family with anti-GBM disease should be directly examined in human patients, not only in animal models. Other pathways involved in target organ lesion, such as renin-angiotensin system, inflammatory cascades are warranted to be checked in human anti-GBM disease.

\section{Future Directions}

Although there has been considerable progress in our understanding of human anti-GBM disease, more studies need to be done. In this context, genetic studies are important not only because they help identify genetic variability associated with anti-GBM disease, but also because they help elucidate pathological mechanisms while providing diagnostic tools and clues for therapy optimization. Over the last year, new genes have been associated with anti-GBM disease. Specifically, in addition to HLA genes, genes of FCGR and KLK families have been found to modulate the susceptibility to the disease $[36,37,56,58]$. These recent findings reinforce the concept of the complexity of anti-GBM disease and emphasize the importance of investigating biologically relevant pathways [59]. Since the rarity of the disease limits the number of studies that can be conducted in humans, inter- or intranational and interdisciplinary collaborations will be tremendously important to the progress of our understanding of the genetics of antiGBM disease.

Novel integrative approaches will also be crucial for the progress of our understanding of anti-GBM disease. Such approaches may include:

- Learning lessons from other autoimmune diseases. Anti-GBM disease has long been used as a model to study immunological aspects of other autoimmune diseases [6]; reciprocally, other autoimmune diseases may provide important clues to the genetics of anti-GBM disease. The recent and reliable data from genome-wide association studies would be particularly insightful in identifying genetic risk variants. Such a strategy has been successfully applied in lupus and ANCA-associated systemic vasculitis. Although difficult, a hypothesis-free genome-wide association study strategy will be an important way to look for novel pathways involved in the pathogenesis of anti-GBM disease and to validate existing data $[59,60]$.

- Integration of SNP, CNV and deep sequencing data for fine mapping and discovering individually rare variants. The difficulty to discover susceptibility genes or responsible variants within associated genetic regions and the insensitivity to rare variants and structural variants in previous genetic studies emphasize the necessity of integrating SNP, CNV and deep sequencing data for fine mapping. Under the 'common variants/ multiple disease' hypothesis, most of the risk alleles identified for various complex diseases are common with small effect sizes (odds ratio $<1.5$ ). Thus, the acquired data can account only for a small proportion of heritability. It is speculated that identifying more penetrant alleles with larger functional effects will provide a potentially valuable path towards further discoveries [61]. 
- Expression quantitative trait loci mapping and transcriptome sequencing. Such approaches may provide more functional genetic information. The abundance of a gene transcript can be directly modified by polymorphisms in regulatory elements [62]. Consequently, transcript abundance might be considered as a quantitative trait that can be mapped with considerable power. Recent data suggest that tissue-specific patterns of gene expression are highly inherited. Systematically generated expression quantitative trait loci information could provide immediate insight into a biological basis for disease associations and could help identify networks of genes involved in the disease pathogenesis.

- Integrating genes, environment and epigenetic factors. It is known that environmental factors (e.g. infective agents, hydrocarbon exposure, lithotripsy, urinary obstruction, and cigarette smoking) may play a role in triggering anti-GBM disease. However, it is still unclear how and if environmental stimuli interact with inherited factors. A few studies have successfully found links between environment and genetics. For instance, a link has been found between HLADRB1*1501, vitamin D and multiple sclerosis [22], while another one has been found between HLADRB1*1501, PTPN22, smoking and rheumatoid ar- thritis [63]. Links between genes and environmental factors might help define the precise etiology of antiGBM disease and may be useful for designing effective disease prevention.

\section{Conclusion}

In this review, we attempted to summarize the current knowledge on the pathogenesis of anti-GBM disease by providing different but complementary perspectives. Results from ongoing studies on the genetics of human antiGBM disease will improve our understanding of the pathogenesis of the disease and will help optimize targeted therapy. Such a genetic approach will surely provide insights into the processes that regulate autoimmunity and may be adopted to study other autoimmune kidney diseases.

\section{Acknowledgments}

The work is supported by grants from the National Natural Science Foundation of China (No. 30801022 and No. 30825021) and the Foundation of Ministry of Health of China (No. 200802052). We apologize to those authors whose publications could not be quoted in this review due to space limitations.

\section{References}

1 Chen M, Cui Z, Zhao MH: ANCA-associated vasculitis and anti-GBM disease: the experience in China. Nephrol Dial Transplant 2010;25:2062-2065.

$\checkmark 2$ Pusey CD: Anti-glomerular basement membrane disease. Kidney Int 2003;64:15351550.

- 3 Lin W, Chen M, Cui Z, Zhao MH: The immunopathological spectrum of crescentic glomerulonephritis: a survey of 106 patients in a single Chinese center. Nephron Clin Pract 2010;116:c65-c74.

$\checkmark 4$ Knoll G, Rabin E, Burns BF: Antiglomerular basement membrane antibody-mediated nephritis with normal pulmonary and renal function. A case report and review of the literature. Am J Nephrol 1993;13:494496.

5 Kluth DC, Rees AJ: Anti-glomerular basement membrane disease. J Am Soc Nephrol 1999; 10:2446-2453.

-6 Ooi JD, Holdsworth SR, Kitching AR: Advances in the pathogenesis of Goodpasture's disease: from epitopes to autoantibodies to effector T cells. J Autoimmun 2008;31:295300.
7 Salama AD, Levy JB, Lightstone L, Pusey CD: Goodpasture's disease. Lancet 2001;358: 917-920.

-8 Turner AN: Goodpasture's disease. Nephrol Dial Transplant 2001;16(suppl 6):52-54.

$\checkmark 9$ Borza DB, Neilson EG, Hudson BG: Pathogenesis of Goodpasture syndrome: a molecular perspective. Semin Nephrol 2003;23: 522-531.

10 Pedchenko V, Bondar O, Fogo AB, Vanacore R, Voziyan P, Kitching AR, Wieslander J, Kashtan C, Borza DB, Neilson EG, Wilson $\mathrm{CB}$, Hudson BG: Molecular architecture of the Goodpasture autoantigen in anti-GBM nephritis. N Engl J Med 2010;363:343-354.

11 Yang R, Cui Z, Zhao J, Zhao MH: The role of HLA-DRB1 alleles on susceptibility of Chinese patients with anti-GBM disease. Clin Immunol 2009;133:245-250.

12 Phelps RG, Rees AJ: The HLA complex in Goodpasture's disease: a model for analyzing susceptibility to autoimmunity. Kidney Int 1999;56:1638-1653.
13 Cui Z, Zhao MH, Singh AK, Wang HY: Antiglomerular basement membrane disease with normal renal function. Kidney Int 2007; 72:1403-1408.

14 Borza DB, Netzer KO, Leinonen A, Todd P, Cervera J, Saus J, Hudson BG: The Goodpasture autoantigen. Identification of multiple cryptic epitopes on the $\mathrm{NC1}$ domain of the alpha3(IV) collagen chain. J Biol Chem 2000;275:6030-6037.

15 Persson U, Hertz JM, Carlsson M, Hellmark T, Juncker I, Wieslander J, Segelmark M: Patients with Goodpasture's disease have two normal COL4A3 alleles encoding the NC1 domain of the type IV collagen alpha 3 chain. Nephrol Dial Transplant 2004;19:20302035.

16 Reynolds J, Cook PR, Ryan JJ, Norsworthy PJ, Glazier AM, Duda MA, Evans DJ, Aitman TJ, Pusey CD: Segregation of experimental autoimmune glomerulonephritis as a complex genetic trait and exclusion of COL4A3 as a candidate gene. Exp Nephrol 2002;10: 402-407. 
17 Vanacore RM, Ham AJ, Cartailler JP, Sundaramoorthy $\mathrm{M}$, Todd $\mathrm{P}$, Pedchenko V, Sado $\mathrm{Y}$, Borza DB, Hudson BG: A role for collagen IV cross-links in conferring immune privilege to the Goodpasture autoantigen: structural basis for the crypticity of B cell epitopes. J Biol Chem 2008;283:22737-22748.

- 18 Vanacore RM, Ham AJ, Voehler M, Sanders CR, Conrads TP, Veenstra TD, Sharpless KB, Dawson PE, Hudson BG: A sulfilimine bond identified in collagen IV. Science 2009;325: 1230-1234.

19 Salant DJ: Goodpasture's disease - new secrets revealed. N Engl J Med 2010;363:388-391.

-20 Fernando MM, Stevens CR, Walsh EC, De Jager PL, Goyette P, Plenge RM, Vyse TJ, Rioux JD: Defining the role of the MHC in autoimmunity: a review and pooled analysis. PLoS Genet 2008;4:e1000024.

-21 Miretti MM, Walsh EC, Ke X, Delgado M, Griffiths M, Hunt S, Morrison J, Whittaker P, Lander ES, Cardon LR, Bentley DR, Rioux JD, Beck S, Deloukas P: A high-resolution linkage-disequilibrium map of the human major histocompatibility complex and first generation of tag single-nucleotide polymorphisms. Am J Hum Genet 2005;76:634-646.

22 Ramagopalan SV, Maugeri NJ, Handunnetthi L, Lincoln MR, Orton SM, Dyment DA, Deluca GC, Herrera BM, Chao MJ, Sadovnick AD, Ebers GC, Knight JC: Expression of the multiple sclerosis-associated MHC class II allele HLA-DRB1* 1501 is regulated by vitamin D. PLoS Genet 2009; 5:e1000369.

-23 Phelps RG, Jones V, Turner AN, Rees AJ: Properties of HLA class II molecules divergently associated with Goodpasture's disease. Int Immunol 2000;12:1135-1143.

24 Cui Z, Zhao MH: Avidity of anti-glomerular basement membrane autoantibodies was associated with disease severity. Clin Immunol 2005;116:77-82.

25 Cui Z, Wang HY, Zhao MH: Natural autoantibodies against glomerular basement membrane exist in normal human sera. Kidney Int 2006;69:894-899.

-26 Zhao J, Cui Z, Yang R, Jia XY, Zhang Y, Zhao MH: Anti-glomerular basement membrane autoantibodies against different target antigens are associated with disease severity. Kidney Int 2009;76:1108-1115.

-27 Yang R, Hellmark T, Zhao J, Cui Z, Segelmark M, Zhao MH, Wang HY: Levels of epitope-specific autoantibodies correlate with renal damage in anti-GBM disease. Nephrol Dial Transplant 2009;24:1838-1844.

- 28 Meyers KE, Christensen M, Madaio MP: Modeling of human anti-GBM antibodyalpha3(IV)NC1 interactions predicts antigenic cross-linking through contact of both heavy chains with repeating epitopes on alpha3(IV)NC1. Am J Nephrol 2009;30:474480.
29 Clynes R, Dumitru C, Ravetch JV: Uncoupling of immune complex formation and kidney damage in autoimmune glomerulonephritis. Science 1998;279:1052-1054.

30 Takai T: Roles of Fc receptors in autoimmunity. Nat Rev Immunol 2002;2:580-592.

-31 Nimmerjahn F, Ravetch JV: Fcgamma receptors as regulators of immune responses. Nat Rev Immunol 2008;8:34-47.

32 Smith KG, Clatworthy MR: FcgammarIIB in autoimmunity and infection: evolutionary and therapeutic implications. Nat Rev Immunol 2010;10:328-343.

33 Nakamura A, Yuasa T, Ujike A, Ono M, Nukiwa T, Ravetch JV, Takai T: Fcgamma receptor IIB-deficient mice develop Goodpasture's syndrome upon immunization with type IV collagen: a novel murine model for autoimmune glomerular basement membrane disease. J Exp Med 2000;191:899-906.

34 Kaneko Y, Nimmerjahn F, Madaio MP, Ravetch JV: Pathology and protection in nephrotoxic nephritis is determined by selective engagement of specific Fc receptors. J Exp Med 2006;203:789-797.

35 Tsuboi N, Asano K, Lauterbach M, Mayadas TN: Human neutrophil Fcgamma receptors initiate and play specialized nonredundant roles in antibody-mediated inflammatory diseases. Immunity 2008;28:833-846.

36 Zhou XJ, Lv JC, Yu L, Cui Z, Zhao J, Yang R, Han J, Hou P, Zhao MH, Zhang H: FCGR2b gene polymorphism rather than FCGR2A, FCGR3A and FCGR3B is associated with anti-GBM disease in Chinese. Nephrol Dial Transplant 2010;25:97-101.

37 Zhou XJ, Lv JC, Bu DF, Yu L, Yang YR, Zhao J, Cui Z, Yang R, Zhao MH, Zhang H: Copy number variation of FCGR3A rather than FCGR3B and FCGR2B is associated with susceptibility to anti-GBM disease. Int Immunol 2010;22:45-51.

- 38 Floto RA, Clatworthy MR, Heilbronn KR, Rosner DR, MacAry PA, Rankin A, Lehner PJ, Ouwehand WH, Allen JM, Watkins NA, Smith KG: Loss of function of a lupusassociated FcgammarIIB polymorphism through exclusion from lipid rafts. Nat Med 2005;11:1056-1058.

39 Breunis WB, van Mirre E, Geissler J, Laddach N, Wolbink G, van der Schoot E, de Haas M, de Boer M, Roos D, Kuijpers TW: Copy number variation at the FCGR locus includes FCGR3A, FCGR2C and FCGR3B but not FCGR2A and FCGR2B. Hum Mutat 2009;30:E640-E650.

-40 Willcocks LC, Lyons PA, Clatworthy MR, Robinson JI, Yang W, Newland SA, Plagnol V, McGovern NN, Condliffe AM, Chilvers ER, Adu D, Jolly EC, Watts R, Lau YL, Morgan AW, Nash G, Smith KG: Copy number of FCGR3B, which is associated with systemic lupus erythematosus, correlates with protein expression and immune complex uptake. J Exp Med 2008;205:1573-1582.
41 Lv J, Yang Y, Zhou X, Yu L, Li R, Hou P, Zhang H: FCGR3B copy number variation is not associated with lupus nephritis in a Chinese population. Lupus 2010;19:158-161.

-42 Yang H, Zhou Q, Chen D, Jiang H, Mao Y, Chen J: The single nucleotide polymorphisms gene but not the copy number variation of FCGR3B is associated with lupus nephritis in Chinese people. Lupus 2010;19: 662-664.

43 Niederer HA, Willcocks LC, Rayner TF, Yang W, Lau YL, Williams TN, Scott JA, Urban BC, Peshu N, Dunstan SJ, Hien TT, Phu NH, Padyukov L, Gunnarsson I, Svenungsson E, Savage CO, Watts RA, Lyons PA, Clayton DG, Smith KG: Copy number, linkage disequilibrium and disease association in the FCGR locus. Hum Mol Genet 2010;19: 3282-3294.

-44 Stranger BE, Forrest MS, Dunning M, Ingle CE, Beazley C, Thorne N, Redon R, Bird CP, de Grassi A, Lee C, Tyler-Smith C, Carter N, Scherer SW, Tavare S, Deloukas P, Hurles ME, Dermitzakis ET: Relative impact of nucleotide and copy number variation on gene expression phenotypes. Science 2007;315: 848-853

45 Chen M, Daha MR, Kallenberg CG: The complement system in systemic autoimmune disease. J Autoimmun 2010;34:J276J286.

46 Sylvestre D, Clynes R, Ma M, Warren H, Carroll MC, Ravetch JV: Immunoglobulin Gmediated inflammatory responses develop normally in complement-deficient mice. J Exp Med 1996;184:2385-2392.

47 Sheerin NS, Abe K, Risley P, Sacks SH: Accumulation of immune complexes in glomerular disease is independent of locally synthesized C3. J Am Soc Nephrol 2006;17: 686-696.

48 Robson MG, Cook HT, Botto M, Taylor PR, Busso N, Salvi R, Pusey CD, Walport MJ, Davies $\mathrm{KA}$ : Accelerated nephrotoxic nephritis is exacerbated in Clq-deficient mice. J Immunol 2001;166:6820-6828.

49 Sheerin NS, Springall T, Carroll MC, Hartley B, Sacks SH: Protection against anti-glomerular basement membrane (GBM)-mediated nephritis in C3- and C4-deficient mice. Clin Exp Immunol 1997;110:403-409.

50 Otten MA, Groeneveld TW, Flierman R, Rastaldi MP, Trouw LA, Faber-Krol MC, Visser A, Essers MC, Claassens J, Verbeek JS, van Kooten C, Roos A, Daha MR: Both complement and IgG Fc receptors are required for development of attenuated antiglomerular basement membrane nephritis in mice. J Immunol 2009; 183:3980-3988.

51 Wu J, Hicks J, Borillo J, Glass WN, Lou YH: $\mathrm{CD} 4(+) \mathrm{T}$ cells specific to a glomerular basement membrane antigen mediate glomerulonephritis. J Clin Invest 2002;109:517-524. 
-52 Reynolds J, Norgan VA, Bhambra U, Smith J, Cook HT, Pusey CD: Anti-CD8 monoclonal antibody therapy is effective in the prevention and treatment of experimental autoimmune glomerulonephritis. J Am Soc Nephrol 2002;13:359-369.

53 Ooi JD, Phoon RK, Holdsworth SR, Kitching AR: IL-23, not IL -12, directs autoimmunity to the Goodpasture antigen. J Am Soc Nephrol 2009;20:980-989.

54 Mesnard L, Keller AC, Michel ML, Vandermeersch S, Rafat C, Letavernier E, Tillet Y, Rondeau E, Leite-de-Moraes MC: Invariant natural killer T cells and TGF-beta attenuate anti-GBM glomerulonephritis. J Am Soc Nephrol 2009;20:1282-1292.

55 Xie C, Rahman ZS, Xie S, Zhu J, Du Y, Qin X, Zhou H, Zhou XJ, Mohan C: Strain distribution pattern of immune nephritis - a follow-up study. Int Immunol 2008;20:719728 . $\checkmark 56$ Liu K, Li QZ, Delgado-Vega AM, Abelson AK, Sanchez E, Kelly JA, Li L, Liu Y, Zhou J, Yan M, Ye Q, Liu S, Xie C, Zhou XJ, Chung SA, Pons-Estel B, Witte T, de Ramon E, Bae SC, Barizzone N, Sebastiani GD, Merrill JT, Gregersen PK, Gilkeson GG, Kimberly RP, Vyse TJ, Kim I, D’Alfonso S, Martin J, Harley JB, Criswell LA, Wakeland EK, AlarconRiquelme ME, Mohan C: Kallikrein genes are associated with lupus and glomerular basement membrane-specific antibody-induced nephritis in mice and humans. J Clin Invest 2009;119:911-923.

57 Kakoki M, Smithies O: The kallikrein-kinin system in health and in diseases of the kidney. Kidney Int 2009;75:1019-1030.

58 Zhou XJ, Lv JC, Zhao MH, Zhang H: Klk1 gene polymorphisms are not associated with lupus nephritis in a Chinese Han population. J Rheumatol 2010;37:1359-1360.

59 Hirschhorn JN: Genomewide association studies - illuminating biologic pathways. N Engl J Med 2009;360:1699-1701.
60 Zenewicz LA, Abraham C, Flavell RA, Cho JH: Unraveling the genetics of autoimmunity. Cell 2010;140:791-797.

61 Eichler EE, Flint J, Gibson G, Kong A, Leal SM, Moore JH, Nadeau JH: Missing heritability and strategies for finding the underlying causes of complex disease. Nat Rev Genet 2010;11:446-450

62 Cookson W, Liang L, Abecasis G, Moffatt M, Lathrop M: Mapping complex disease traits with global gene expression. Nat Rev Genet 2009;10:184-194.

63 Mahdi H, Fisher BA, Kallberg H, Plant D, Malmstrom V, Ronnelid J, Charles P, Ding B, Alfredsson L, Padyukov L, Symmons DP, Venables PJ, Klareskog L, Lundberg K: Specific interaction between genotype, smoking and autoimmunity to citrullinated alphaenolase in the etiology of rheumatoid arthritis. Nat Genet 2009;41:1319-1324. 